\title{
Karakterisasi Sifat Fisik Granul Dengan Bahan Pengikat Amylum Manihot Pragelatinasi Dan Polivinilpirolidon
}

\author{
Rela Pamungkas Sari ${ }^{1}$, Dwi Bagus Pambudi ${ }^{2 *}$, St. Rahmatullah ${ }^{3}$, Wulan \\ Agustin Ningrum ${ }^{4}$ \\ 1,2,3,4 Program Studi Sarjana Farmasi, Fakultas Ilmu Kesehatan, Universitas Muhammadiyah \\ Pekajangan Pekalongan, Indonesia \\ *email:dwibagus589@umpp.ac.id
}

\begin{abstract}
Granules come from small particles which then become single larger particles to form a lump. The binder in the granules is used to ensure the incorporation of the powder particles in the granules. Manihot starch is a natural binder and polyvinylpyrrolidone is a synthetic binder, because manihot starch has poor flow properties, it is necessary to modify it by pregelatination. The purpose of this study was to determinethe characterization of the physycal properties of granules with a natural binder of pregelatinized starch manihot and and synthetic polyvinylpyrrolidone on the physical properties of the granules. Variations in the concentration of pregelatinated starch manihot were $3 \%$ and $5 \%$ respectively. The granulation process is carried out by mixing all materials that have easy flowing properties. The resulting granules were evaluated for their physical properties and then the data were analyzed using SPSS with the One Way ANOVA method with a $95 \%$ confidence level. The results of the organoleptic test are white granules but on F1 and F2 there are brown spots then round shape and characteristic odor, the flow time meets the requirements of 10 $\mathrm{g} /$ second, the angle of repose test meets the requirements $<30^{\circ}$, compressibility meets the requirements $<15 \%$. The results of statistical analysis showed a significant difference (sig $<0,05)$ in the flow time test. The optimum concentration of pregelatiansi manihot starch is $5 \%$ (F2) and polyvinylpyrrolidone 5\% (F4). The Suggest for further researchers can use other natural excipients and make modifications to improve the physical characteristics of the granules.
\end{abstract}

Keyword: Amylum Manihot; granules;polivinilpirolidon; pragelatination

\begin{abstract}
Abstrak
Granul berasal dari partikel-partikel yang berukuran kecil kemudiam menjadi partikel tunggal yang lebih besar membentuk suatu gumpalan. Bahan pengikat pada granul digunakan untuk menjamin penyatuan partikel serbuk dalam granul. Amilum manihot merupakan pengikat bahan alami dan polivinilpirolidon merupakan pengikat bahan sintetis, dikarenakan amilum manihot memiliki sifat alir yang kurang baik maka perlu dilakukan modifikasi dengan pragelatinasi. Tujuan dari penelitian ini untuk mengetahui karakterisasi sifat fisik granul dengan bahan pengikat alami amilum manihotpragelatinasi dan bahan sintetis polivinilpirolidon. Variasi konsentrasi bahan pengikat masing-masing adalah $3 \%$ dan $5 \%$. Proses granulasi dilakukan dengan mencampurkan seluruh bahan yang memiliki sifat mudah mengalir. Granul yang dihasilkan di evaluasi sifat fisiknya kemudian data dianalisis menggunakan SPSS dengan metode One Way ANOVA dengan tingkat kepercayaan 95\%. Hasil uji organoleptisgranulbewarna putih namun pada F1 dan F2 terdapat bintik coklat kemudian bentuk bulat dan bau khas, waktu alir memenuhi syarat $\leq 10 \mathrm{~g} /$ detik, uji sudut diam memenuhi syarat $<30^{\circ}$, kompresibilitas memenuhi syarat $<15 \%$. Hasil analisis statistik terdapat perbedaan bermakna (sig $<0,05)$ pada uji waktu alir.Konsentrasi optimum bahan pengikat amylummanihotpragelatiansi 5\% (F2) dan polivinilpirolidon 5\% (F4). Saran untuk
\end{abstract}




\section{Prosiding Seminar Nasional Kesehatan Lembaga Penelitian dan Pengabdian Masyarakat Universitas Muhammadiyah Pekajangan Pekalongan}

peneliti selanjutnya dapat digunakan bahan eksipien alami yang lainnya dan dilakukan modifikasi untuk meningkatkan karakteristik sifat fisik granul.

Kata kunci: Amilum Manihot; granul;polivinilpirolidon; pragelatinasi

\section{Pendahuluan}

Granul adalah suatu gumpalan yang berasal dari partikel-partikel yang memiliki ukuran lebih kecil yang memiliki bentuk tidak merata kemudian menjadi partikel tunggal yang lebih besar (Ansel,1989). Granulasi serbuk ialah proses membesarkan ukuran partikel kecil yang dikumpulkan bersama-sama menjadi agregat (gumpalan) yang lebih besar, secara fisik lebih kuat dan partikel orisinil masih teridentifikasi dan membuat agregat mengalir bebas (Rhamdani, 2019)

Bahan tambahan yang memiliki peran penting dalam pembuatan granul adalah bahan pengikat.Bahan pengikat berfungsi untuk memberikan kekompakkan dan daya tahan tablet, sehingga dapat menjamin penyatuan beberapa partikel serbuk dalam sebuah butir granul (Voigt, 1984).Bahan pengikat terdiri dari bahan alami dan polimer sintetis. Salah satu bahan pengikat bahan sintetis yang sering digunakan adalah polivinilpirolidon.Menurut penelitian Putra, et. al., (2019) granul dengan polivinilpirolidon memiliki sifat alir yang baik, sudut diam minimum, menghasilkan fines lebih sedikit dan daya kompaktibilitasnya lebih baik. Bahan pengikat alami yang paling sering digunakan adalah amilum manihot namun masih memiliki banyak kekurangan diantaranya yaitu memliki sifat alir dan kompresibilitas yang kurang baik maka dari itu diperlukanya modifikasi secara fisik dengan pragelatinasi (Setiawati, et al. 2020).

Pati pragelatinasi merupakan pati yang dibuat dengan melalui proses pemanasan pada suhu gelatinasinya kemudian dikeringkan. Pati pragelatinasi terdiri dari pati utuh dan pati yang telah mngalami pemecahan akibat proses pemanasan yang membentuk ukuran partikel lebih besar sehingga memiliki sifat alir dan daya kompresibilitas yang baik. Metode pragelatinasi pada pati memiliki ukuran distribusi partikel yang lebih besar dibandingkan dengan pati tanpa modifikasi (Mariyani, et. al., 2012). Dewi, et al. (2021) menyatakan bahwa amilum manihotpragelatinasi menghasilkan sifat fisik granul yaitu waktu alir granul lebih cepat, sudut diam yang baik dan nilai kompaktibilitas yang sedikit menunjukan ikatan antar massa serbuk yang baik.

Berdasarkan uraian diatas, pada penelitian ini akan dilakukan penelitian mengenaii karakteristik sifat fisik granul dengan menggunakan bahan pengikat amilum manihot dan polivinilpirolidon. Tujuan dari penelitian ini yaitu untuk mengetahui karakterisasi sifat fisik granul dengan bahan pengikat amilum manihot dan polivinilpirolidon.

\section{Metode}

\section{Alat dan Bahan}

Alat yang digunakan dalam penelitian ini adalah oven, ayakan mesh 80 dan 20, alat gelas (pyrex), gelas ukur $100 \mathrm{~mL}$ (pyrex), waterbath, stopwatch, wadah, timbangan analitik (Ohauss), granul flow tester (Lokal), pisau dan blender.

Bahan yang digunakan yaitu singkong yang didapatkan di wilayah Desa Kreyo, Randudongkal, kalsium laktat (PT. Brataco), polivinilpirolidon (PT. Brataco), primogel (PT. Brataco), mg stearat (PT. Brataco) dan laktosa (PT. Brataco). 


\section{Prosiding Seminar Nasional Kesehatan Lembaga Penelitian dan Pengabdian Masyarakat Universitas Muhammadiyah Pekajangan Pekalongan

\section{Prosedur Penelitian}

1. Pembuatan amilum manihotpragelatinasi

Pembuatan amilum diawali dengan menghaluskan singkong yang telah dicuci bersih sebanyak $5 \mathrm{~kg}$.Singkong yang telah halus ditambahkan air dengan perbandingan 1:2 (b/v). Rendaman air dan singkong halus didiamkan 24 jam kemudian diperasmenggunakan kainuntuk memisahkan air dan serat singkong.Air hasil perasan didiamkan hingga terbentuk endapan yang mengandung amilum atau pati.Amilum yang mengendap kemudian dikeringkan di dalam oven dengan suhu $60^{\circ} \mathrm{C}$ hingga kadar air berkurang.

Proses modifikasi sifat fisik dengan pragelatinasi diawali dengan mempersiapkan pati singkong kering dan aquadest dengan perbandingan $1: 1$ (b:v). Suspensi campuran air dan pati singkong dipanaskan pada suhu $60^{\circ} \mathrm{C}$ selama 10 menit dan diaduk secara konstan. Suspensi kental dipanaskan di dalam oven dengan suhu $60^{\circ} \mathrm{C}$ selama 24 jam kemudian dilakukan pengayakan dengan mesh 20.

2. Preparasigranul

Tabel 1. Formulasi granul

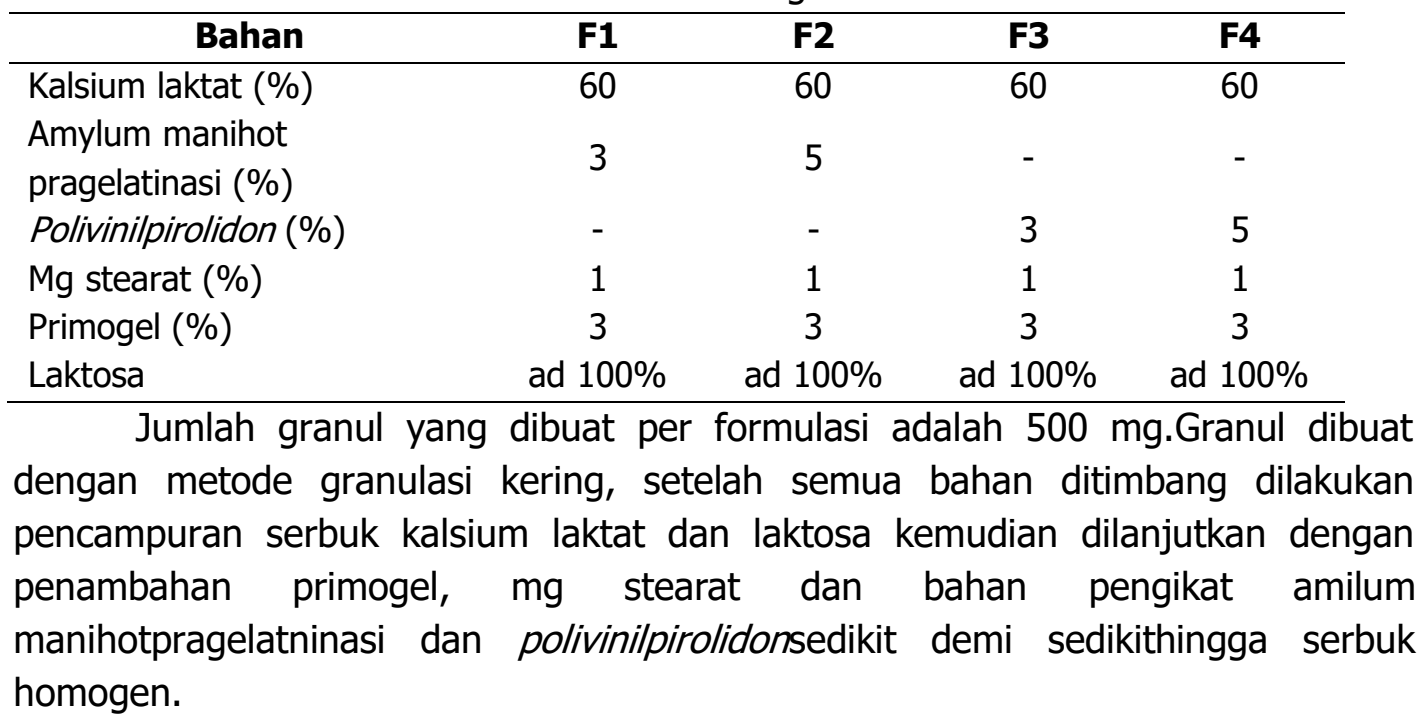

3. Evaluasi Granul

\subsection{Organoleptis}

Granul yang dihasilkan diamati secara langsung dan seksama melalui indra penglihatan meliputi bentuk, warna dan bau.

\subsection{Uji waktu alir}

Pengujan sifat alir menggunakan metode corong dengan menimbang 25 gr granul kemudian dimasukan kepada corong.Ketika penutup dibuka hitung waktu yang dibutuhkan serbuk untuk keluar.Kecepatan $>10 \mathrm{gr} /$ detik bebas mengalir dan 4-10 g/detik mudah mengalir (Siregar dan Wikarsa, 2010). Pengujian diulang sebanyak tiga kali kemudian dihitung waktu alir granul dengan rumus :

$$
\text { Kecepatan alir serbuk }=\frac{\operatorname{bobot}(g)}{w a k t u(\operatorname{det} i k)}
$$




\section{Prosiding Seminar Nasional Kesehatan \\ Lembaga Penelitian dan Pengabdian Masyarakat Universitas Muhammadiyah Pekajangan Pekalongan

\subsection{Uji sudut diam}

Pengujian sudut diam menggunakan metode sudut istirahat dengan mengalirkan 25 gr serbuk granul kedalam corong dan jatuh diatas kertas grafik yang membentuk kerucut kemudian sudut istirahatnya dapat diukur. Nilai sudut istirahat $\leq 30^{\circ}$ menunjukkan bahwa granul mengalir bebas (Lachman, et. al., 2008). Pengujian sudut diam diulang sebanyak tiga kali kemudian dihitung sidit diam granul dengan rumus :

$$
\operatorname{Tan} \theta=\frac{2 h}{D}
$$

Keterangan : $\quad \tan \theta=\operatorname{sudut} \operatorname{diam}\left({ }^{\circ}\right)$

$\mathrm{h} \quad=$ tinggi kerucut $(\mathrm{mm})$

$\mathrm{d}=$ diameter $\operatorname{kerucut}(\mathrm{mm})$

3.4 Uji bobot jenis nyata

Granul dimasukan kedalam gelas ukur $100 \mathrm{~mL}$ kemudian ditimbang dan dicatat berat granulnya. Ulangi pengujian sebanyak tiga kali kemudian dihitung bobot jenis dengan rumus :

$$
\text { Bobot jenis nyata }(\rho 0)=\frac{\text { berat granul }(g)}{\text { volume granul }(m L)}
$$

\subsection{Uji bobot jenis mampat}

Granul dimasukan kedalam gelas ukur $100 \mathrm{~mL}$ kemudian ditimbang berat granulnya.Gelas ukur yang berisi granul sebanyak $100 \mathrm{~mL}$ dimasukan kedalam alat pengetapan hingga volumenya konstan. Dicatat volume mampat granul, pengujian diulangi sebanyak tiga kali kemudian dihitung bobot jenis mampatnya dengan rumus:

$$
\text { Bobot jenis mampat }(\rho t)=\frac{\text { berat granul }(g)}{\text { volume } \operatorname{mampat}(m L)}
$$

\subsection{Uji kompresibilitas}

Pengujian kompesibilitas digunakan untuk mengetahui kemampuan dari formula granul ini untuk dicetak menjadi massa tablet, nilai kompresibilitas dibawah $15 \%$ memberikan sifat alir yang baik dan diatas $15 \%$ menunjukkan kemampuan alir yang buruk (Lachman etal., 2008). Uji komresibilitasgranul dapat dihitung dengan rumus :

$$
\% \text { Kompresibilitas }=\frac{\rho \mathrm{t}-\rho 0}{\rho \mathrm{t}} \times 100 \%
$$

\section{Analisis Data}

Untuk mengetahui perbedaan bahan pengikat amilum manihotpragelatinasi dan poilivinilpirolidon yang digunakan pada formulasi dilakukan dengan analisis data SPSS metode one way ANOVA (Anlysis of Variance) dengan taraf kepercayaan 95\%. Jika hasil one way ANOVA<0,05 maka dilanjutkan dengan uji Tukey HSD untuk memperjelas perbedaan masing-masing konsentrasi bahan pengikat yang digunakan. 


\section{Prosiding Seminar Nasional Kesehatan Lembaga Penelitian dan Pengabdian Masyarakat Universitas Muhammadiyah Pekajangan Pekalongan}

\section{Hasil dan Pembahasan}

\section{Hasil}

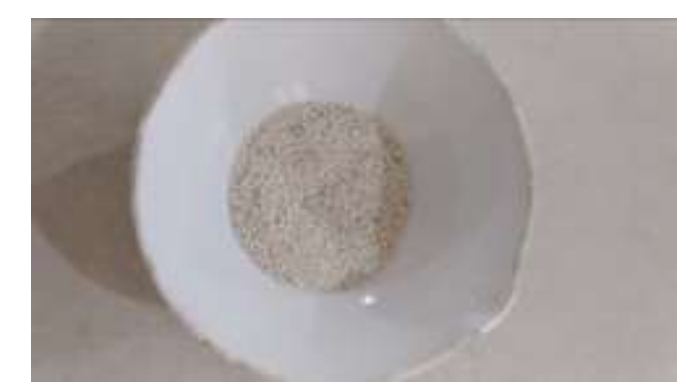

Gambar 1. Amylum manihot pragelatinasi

\section{Evaluasi granul}

1. Organoleptis

Tabel 2. Hasil pengujian organoleptisgranul

\begin{tabular}{cccc}
\hline Formulasi & Bentuk & Warna & Bau \\
\hline F1 & Bulat & Putih ada bintik coklat & Khas \\
F2 & Bulat & Putih ada bintik coklat & Khas \\
F3 & Bulat & Putih & Khas \\
F4 & Bulat & Putih & \\
\hline
\end{tabular}

2. Uji waktu alir

Tabel 3. Hasil pengujian waktu alir

\begin{tabular}{|c|c|c|c|c|c|}
\hline \multirow{2}{*}{ Formulasi } & \multicolumn{3}{|c|}{ Waktu alir (g/detik) } & \multirow{2}{*}{ Rata-rata } & \multirow[t]{2}{*}{ Keterangan } \\
\hline & 1 & 2 & 3 & & \\
\hline $\mathrm{F} 1$ & 20 & 24,5 & 23,8 & 22,77 & Memenuhi syarat \\
\hline $\mathrm{F} 2$ & 25,25 & 29,41 & 28,73 & 27,80 & Memenuhi syarat \\
\hline F3 & 13,36 & 17,24 & 16,77 & 15,79 & Memenuhi syarat \\
\hline $\mathrm{F} 4$ & 20,16 & 23,8 & 21,55 & 21,84 & Memenuhi syarat \\
\hline
\end{tabular}

3. Uji sudut diam

Tabel 4. Hasil pengujian sudut diam

\begin{tabular}{cccccc}
\hline \multirow{2}{*}{ Formulasi } & \multicolumn{3}{c}{ Sudut diam $\left(^{\circ}\right)$} & \multirow{2}{*}{ Rata-rata } & Keterangan \\
\cline { 2 - 4 } & $\mathbf{1}$ & $\mathbf{2}$ & $\mathbf{3}$ & & \\
\hline F1 & 25,6 & 22,3 & 24,3 & 23,43 & Memenuhi syarat \\
F2 & 22 & 21,8 & 23,4 & 22,40 & Memenuhi syarat \\
F3 & 23 & 23,3 & 22 & 22,77 & Memenuhi syarat \\
F4 & 23 & 23,4 & 22 & 22,80 & Memenuhi syarat \\
\hline
\end{tabular}

4. Bobot jenis nyata

Tabel 5. Hasil pengujian bobot jenis nyata

\begin{tabular}{ccccc}
\hline \multirow{2}{*}{ Formulasi } & \multicolumn{3}{c}{ Bobot jenis nyata $\mathbf{( g / \mathbf { m L } )}$} & \multirow{2}{*}{ Rata-rata } \\
\cline { 2 - 4 } & $\mathbf{1}$ & $\mathbf{2}$ & $\mathbf{3}$ & \\
\hline F1 & 0,4552 & 0,4562 & 0,4559 & 0,4559 \\
F2 & 0,4550 & 0,4549 & 0,4552 & 0,4552 \\
F3 & 0,4544 & 0,4561 & 0,4555 & 0,4555 \\
F4 & 0,4546 & 0,4545 & 0,4550 & 0,4550 \\
\hline
\end{tabular}




\section{Prosiding Seminar Nasional Kesehatan Lembaga Penelitian dan Pengabdian Masyarakat Universitas Muhammadiyah Pekajangan Pekalongan}

5. Bobot jenis mampat

Tabel 6. Hasil pengujian bobot jenis mampat

\begin{tabular}{ccccc}
\hline Formulasi & \multicolumn{3}{c}{ Bobot jenis mampat $\mathbf{( g / \mathbf { m L } )}$} & \multirow{2}{*}{ Rata-rata } \\
\cline { 2 - 4 } & $\mathbf{1}$ & $\mathbf{2}$ & $\mathbf{3}$ & \\
\hline F1 & 0,4892 & 0,4690 & 0,4840 & 0,4807 \\
F2 & 0,4641 & 0,4738 & 0,4689 & 0,4689 \\
F3 & 0,4636 & 0,4684 & 0,4783 & 0,4701 \\
F4 & 0,4686 & 0,4735 & 0,4638 & 0,4686 \\
\hline
\end{tabular}

6. Uji kompresibilitas

Tabel 7. Hasil pengujian kompresibilitas

\begin{tabular}{|c|c|c|c|c|c|}
\hline \multirow{2}{*}{ Formulasi } & \multicolumn{3}{|c|}{ Kompresibilitas (\%) } & \multirow{2}{*}{ Rata-rata } & \multirow[t]{2}{*}{ Keterangan } \\
\hline & 1 & 2 & 3 & & \\
\hline $\mathrm{F} 1$ & 6,99 & 2,98 & 5,99 & 5,32 & Memenuhi syarat \\
\hline F2 & 1,98 & 3,98 & 2,98 & 2,98 & Memenuhi syarat \\
\hline F3 & 1,98 & 2,98 & 4,09 & 3,02 & Memenuhi syarat \\
\hline $\mathrm{F} 4$ & 2,98 & 3,99 & 1,98 & 3,32 & Memenuhi syarat \\
\hline
\end{tabular}

\section{Hasil analisis statistik}

Tabel 8. Hasil analisis statistik

\begin{tabular}{lcc}
\hline \multicolumn{1}{c}{ Parameter } & Sign. & Keterangan \\
\hline Waktu alir & 0,001 & Ada perbedaan bermakna \\
Sudut diam & 0,309 & Tidak ada perbedaan bermakna \\
Bobot jenis nyata & 0,161 & Tidak ada perbedaan bermakna \\
Bobot jenis mampat & 0,210 & Tidak ada perbedaan bermakna \\
Kompresiilitas & 0,169 & Tidak ada perbedaan bermakna \\
\hline
\end{tabular}

\section{Pembahasan}

Pada penelitian yang dilakukan bertujuan untuk mengetahui karakterisasi sifat fisik granul dengan bahan pengikat amilum manihot dan polivinilpirolidon. Tahap pertama yang dilakukan adalah pembuatan amilum manihot yang berasal dari tanaman singkong.Singkong yang telah dikupas yang dicuci bersih sebanyak $5 \mathrm{~kg}$ dihaluskan menggunakan blender dengan tujuan untuk memecah dinding sel sehingga kandungan pati dapat ditarik keluar.Singkong yang telah halus ditambahkan air dengan perbandingan 2:1 (b/v) dan direndam selama 24 jam. Langkah selanjutnya yaitu diperas menggunakan kain dengan cara meremas-meras hingga airnya dapat terpisah dari ampas singkongnya. Air hasil perasan didiamkan hingga amilum dapat mengendap. Sifat amilum yang tidak larut dalam air menyebabkan proses pengendapan terjadi. Amilum yang mengendap dikeringkan dalam oven hingga kadar amilum manihot menjadi 0,6\% memenuhi persyaratan Depkes RI, 1995 yaitu tidak boleh lebih dari $15 \%$.

Proses pragelatinasi diawali dengan menimbang $200 \mathrm{gr}$ amilum manihot kemudian dicampurkan dengan aquadest $200 \mathrm{~mL}$ dan dilakukan pemanasan selama 10 menit pada suhu $60^{\circ} \mathrm{C}$ yaitu pada suhu pragelatinasi sehingga dapat menghasilkan amilum pragelatinasi yang terdiri dari pati utuh dan pati yang telah mengalami pemecahan akibat proses pemanasan. Suspensi yang dihasilkan dikeringkan selama 24 jam di dalam oven kemudian di ayak dengan ayakan mesh 20. Ukuran partikel amilum 


\section{Prosiding Seminar Nasional Kesehatan Lembaga Penelitian dan Pengabdian Masyarakat Universitas Muhammadiyah Pekajangan Pekalongan}

manihotpragelatinasi yang dihasilkan lebih besar dibandingkan dengan amilum manihot alami hal ini sesuai dengan penelitian yang dilakukan oleh Mariyani, et. al., (2012) bahwa ukuran partikel amilum pragelatinasi lebih besar diakibatkan oleh mengembangnya amilum pada proses pragelatinasi dan granul-granul amilum tersusun bergerombol dan terikat dengan kuat. Proses granulasi dilakukan dengan mencampur seluruh bahan hingga homogen kemudian dapat dilakukan pengujian sifat fisik granul.

Hasil pengujian organoleptisyang terdapat pada tabel 2 memliki bentuk dan bau yang sama yaitu berbentuk bulat dan berbau khas. Warna dari formulasi F1 dan F2 berbeda dengan formulasi F3 dan F4 dikarenakan pada F1 dan F2 menggunakan bahan pengikat amilum manihotpragelatinasi yang memiliki ukuran partikel yang lebih besar dan warna yang sedikit kecoklatan yang disebabkan oleh pemanasan pada saat proses pragelatinasi.

Uji waktu alir dilakukan untuk mengetahui kecepatn granulnya baik atau tidak, granul dengan aliran yang kurang baik akan menyebabkan aliran granul dari hooper ke dalam die tidak sempurna dan akan menyebabkan ketidak seragaman bobot dalam proses pencetakan tablet karena bobot yang dihasilkan tidak konstan. Sifat aliran dipengaruhi oleh bentuk partikel, ukuran partikel dan kadar air. Hasil pengujian waktu alir yang terdapat pada tabel 3 menunjukan pada semua formulasi memenuhi persyaratan yaitu $>10 \mathrm{~g} /$ detik (Cartensen, 1997). Aliran serbuk dapat dipengaruhi oleh ukuran partikel melalui gaya kohesi diantara partikel (Voigt, 1995). Dalam percobaan ini kualitas granulakan semakin baik apabila kecepatan alirnya semakin cepat. Dengan demikian proses pragelatinasi pada amilum manihot yang menyebabkan ukuran partikel lebih besar dapat meningkatkan waktu alir dari granul. Semakin meningkat konsentrasi bahan pengikat amilum manihotpragelatinasi dan polivinilpirolidon maka akan meningkatkan waktu alir yang dihasilkan.

Pengukuran sudut diam dilakukan dengan mengukur diameter lingkaran kerucut serbuk dan tinggi puncak yang terbentuk. Pengukuran menggunakan metode sudut istirahat yaitu sudut maksimil yang dibentuk oleh permukaan serbuk dengan permukaan yang horizontal pada waktu berputar. Tujuan dilakukanya pengujian ini yaitu untuk menjamin sifat aliran yang baik. Hasil dari pengujian sudut diam pada tabel 4.menunjukan bahwa sudut diam pada semua formulasi yaitu $\leq 30^{\circ}$ yang menunjukan granul mengalir bebas. Peningkatan konsentrasi bahan pengikat amilum manihotpragelatinasi dan polivinilpirolidon dapat menyebabkan sudut diam yang terbentuk semakin kecil sehingga sifat aliran serbuk semakin baik. Menurut Kalalo, et. al., (2019) sudut diam yang terbentuk dipengaruhi oleh ukuran partikel, semakin kecil ukuran partikel maka kohesivitas partikel makin tinggi yang akan mengurangi kecepatan alirnya sehingga sudut diam yang terbentuk semakin besar dengan demikian proses pragelatinasi yang dilakukan pada amilum manihot yang menyebabkan ukuran partikel granul menjadi lebih besar dapat ditambahkan ke dalam formula granul untuk meningkatkan sifat alir dan mengurangi sudut diam yang terbentuk.

Bobot jenis nyata merupakan pembagian bobot granul dengan volume granul termasuk didalamya terdapat ruang antar partikel dan ruang intra partikel. Hasil pengujian pada tabel 5 menunjukkan bobot jenis nyata dengan bahan pengikat amilum 


\section{Prosiding Seminar Nasional Kesehatan 2021 Lembaga Penelitian dan Pengabdian Masyarakat Universitas Muhammadiyah Pekajangan Pekalongan}

manihotpragelatinasi pada $\mathrm{F} 1$ dan $\mathrm{F} 2$ berturut-turut yaitu $0,4559 \mathrm{~g} / \mathrm{mL}$ dan 0,4552 $\mathrm{g} / \mathrm{mL}$ sedangkan dengan bahan pengikat polivinilpirolidon pada F3 dan F4 adalah $0,4555 \mathrm{~g} / \mathrm{mL}$ dan $0,4550 \mathrm{~g} / \mathrm{mL}$.Semakin meningkat konsentrasi bahan pengikat maka semakin kecil bobot jenis nyata dikarenakan semakin meningkatnya konsentrasi bahan pengikat maka ukuran partikelnya semakin besar sehingga kerapatan yang terbentuk semakin kecil, hal ini yang menyebabkan semakin kecilnya nilai bobot jenis nyata granul.

Bobot jenis mampat adalah bobot granul dibagi dengan volume granul termasuk didalamnya ruang intra partikel, ruang antar partikel telah dihilangkan dengan pengetukan sehingga diperoleh volume konstan granul. Bobot jenis mampat dipengaruhi oleh bentuk partikel, granul yang seragam akan mempermudah menjadi bentuk mampatnya karena rongga antar granul akan semakin sedikit. Rata-rata hasil pengujian bobot jenis mampat pada tabel 6 menunjukkan dengan bahan pengikat amilum manihotpragelatinasi pada $F 1$ dan $F 2$ yaitu $0,4807 \mathrm{~g} / \mathrm{mL}$ dan $0,4689 \mathrm{~g} / \mathrm{mL}$ kemudian dengan bahan pengikat polivinilpirolidon pada F3 dan F4 adalah 0,4701 $\mathrm{g} / \mathrm{mL}$ dan $0,4686 \mathrm{~g} / \mathrm{mL}$. Semakin besar konsentrasi bahan pengikat bobot jenis mampat semakin mengecil hal ini sesuai dengan penelitian Kalalo, et. al., (2019) bahwa ukuran granul yang bertambah besar dapat meningkatkan kecepatan bulk menurun, dan granul yang kecil akan membentuk massa yang kompak dibandingkan dengan granul besar.

Nilai kompresibilitas merupakan nilai yang berasal dari selisih antara densitas mampat dengan densitas bulk dari granul dibagi dengan densitas mampat. Nilai kompresibilitas menunjukan suatu kerapatan granul dimana bilai kompresibilitas yang tinggi menjadikan granul yang susah mengalir begitupun sebaliknya. Hasil dari pengujian pada tabel 7 menunjukkan nilai kompresibilitas pada semua formulasinilai kompresibilitas memenuhi syarat yaitu < 15\% (Lachman, et. al., 2008). Pada formulasi F1 dan F2 dengan bahan pengikat pati singkong pragelatinasi menunjukan penurunan nilai kompresibilitas yaitu semakin kecil nilai kompresibilitasnya maka granulakan mudah mengalir.

Hasil analisis statistik pada tabel 8 dengan menggunakan metode one way ANOVA pada parameter pengujian sudut diam, bobot jenis nyata, bobot jenis mampat dan kompresibilitas pada granul pada formulasi F1, F2, F3 dan F4 menunjukan bawa tidak ada perbedaan yang bermakna terkait perbedaan bahan pengikat antara amilum manihotpragelatinasi dan polivinilpirolidonterhadap sifat fisik granul dengan menunjukan nilai sign $>0,05$. Pada uji waktu alir granul menunjukan nilai sign $<0,05$ dengan demikian terdapat perbedaan yang bermakna pada bahan pengikat antara amilum manihotpragelatinasi dan polivinilpirolidon terhadap sifat fisik granul. Dilakukan uji lanjutan dengan uji Tukey HSD menunjukan perbedaan pada F3 dengan bahan pengikat polivinilpirolidon 3\% memiliki perbedaan yang bermakna pada F1, F2 dan F4 kemudian pada F2 dengan bahan pengikat amilum manihotpragelatinasi $5 \%$ berbeda bermakna pada F4 dengan bahan pengikat polivinilpirolidon $5 \%$.

\section{Kesimpulan}

Bahan pengikat amilum manihotpragelatinasi dan polivinilpirolidon yang digunakan sebagai bahan pengikat pada semua formulasi memenuhi persyaratan sifat 


\section{Prosiding Seminar Nasional Kesehatan 2021 Lembaga Penelitian dan Pengabdian Masyarakat Universitas Muhammadiyah Pekajangan Pekalongan}

fisik granul yang baik. Hasil analis statistik sifat fisik granul memiliki perbedaan yang bermakna pada uji waktu alir (sig $<0,05$ ). Konsentrasi bahan pengikat dalam formulasi granul paling optimum yaitu bahan pengikat amylummanihotpragelatiansi $5 \%$ (F2) dan polivinilpirolidon 5\% (F4).

\section{Referensi}

[1] Ansel, H.C, "Pengantar Bentuk Sediaan Farmasi" edisi keempat. Jakarta : Universitas Indonesia Press, 2005.

[2] Carstensen, J. T, "Pharmaceutics of Solids and Solid Dosage Forms". New York: Wiley Interscience Publication. 1997.

[3] Depkes RI,"Farmakope Indonesia'Edisi IV. Jakarta: Departemen Kesehatan Republik Indonesia.1995.

[4] Dewi puspita, S.P., Prasetia Jemmy, A.I.G.N dan Arisanti C.I.S, "Pengaruh Amilum Manihot Partially pregelatinized sebagai Penghancur IntragranularEkstragranular pada Formulasi Tablet Ekstrak Daun Ubi Jalat Merah (Ipomoea batatas L.)"Jurnal IImian Medicamento. (1). 62-70. 2021.

[5] Kalalo, Tekla.,Yamlean, P.V.Y., Citraningtyas, G, "Pengaruh Penggunaan Pati Kulit Nanas (Ananascomosus L. Merr.) Sebagai Bahan Pengiikat Pada Granul CTM"Jurnal Pharmacon.8(1).Pp 203-213. 2019.

[6] Lachman, C.L, Lieberman H.A., J.L Kanig.eds, "Teori dan Praktek Farmasi Industri" edisi 2 (Terjemahan). Jakarta : Universitas Indonesia Press. 2008.

[7] Mariyani, K.A., Arisanti, C.I.S. dan Setyawan, E.I, "Pengaruh Amilum Jagung Pregelatinasi Sebagai Bahan Penghancur Terhadap Sifat Fisik Tablet Vitamin E Untuk Anjing"Jurnal Farmasi Udayana. 1(1).39-49. 2012.

[8] Putra, D.J.S., Antari, N.W.Y., Putri, N.P.R.A., Arisanti, C.I.S. dan Samirana. P.O., "Penggunaan PolivinilPirolidon (PVP) Sebagai Bahan Pengikat Pada Formulasi Tablet Ekstrak Daun Sirih (Piper bettle L.)"Jurnal Farmasi udayana.8(1).14-21. 2019.

[9] Ramdhani, Januarta, "Formulasi dan Evaluasi Sifat Fisik Granul Daun Binahong (Anredera cordifoliaTen.) Sebagai Pakan Ayam Broiler (Gallus gallus domestica Sp.)" Karya Tulis Ilmiah. Universitas Muhammadiyah Mataram.2021.

[10] Setiawati, H., Buang, A., Rusli.,Stevanu, H. Dan Dewi, R, "Pemanfaatan Pati Singkong Tergelatinasi Sebagai Pengikat Tablet Asetosal Yang Dibuat Dengan Metode Kempa Langsung" Media Farmasi Poltekkes Makassar. 16(2).222-229. 2021.

[11] Voight, R, "Buku Pelajaran Teknologi Farmasi" Yogyakarta : Gajah Mada University Press. 1995. 